\title{
Zaprinast, a Phosphodiesterase 5 Inhibitor, Overcomes Sexual Dysfunction Produced by Fluoxetine, a Selective Serotonin Reuptake Inhibitor in Hamsters
}

\author{
Cheryl A Frye*,1,2,3 and Madeline E Rhodes' \\ 'Department of Psychology, The University at Albany, SUNY, Albany, NY, USA; ${ }^{2}$ Department of Biological Sciences, The University at Albany, \\ SUNY, Albany, NY, USA; ${ }^{3}$ The Center for Neuroscience Research, The University at Albany, SUNY, Albany, NY, USA
}

\begin{abstract}
A high incidence of sexual dysfunction among women is reported in the clinical literature. Little experimental investigation has been initiated on the ability of phosphodiesterase (PDE) inhibitors to overcome deficits in sexual functioning because of selective serotonin reuptake inhibitors (SSRIs). The effects of fluoxetine, an SSRI, and zaprinast, a PDE-5 inhibitor, on the lateral displacement response (used as a measure of sensitivity to reproductively relevant stimuli) of hamsters in behavioral estrus were investigated. In Experiment I, hamsters that were maximally sensitive to reproductively relevant stimuli because they were at the peak of behavioral estrus were administered fluoxetine $(10 \mathrm{mg} / \mathrm{kg}$, i.p.); they had significantly decreased lateral displacement responses compared to vehicleadministered hamsters. In Experiment 2, hamsters that were relatively less sensitive to sexual stimuli because they were at the termination of behavioral estrus were administered zaprinast $(3 \mathrm{mg} / \mathrm{kg}$; i.p.); they had significantly enhanced lateral displacement responses compared to responses seen following vehicle administration. In Experiment 3, fluoxetine-induced deficits in the lateral displacement of hamsters at the peak of behavioral estrus were overcome by the coadministration of zaprinast. These data confirm previous findings that sexual dysfunction can be induced by SSRIs and extend the current knowledge to suggest that administration of a PDE-5 inhibitor can override SSRI-induced deficits in sexual functioning.
\end{abstract}

Neuropsychopharmacology (2003) 28, 310-316. doi: I0.1038/sj.npp. 130005 I

Keywords: sexual dysfunction; lordosis; female sexual behavior; rodents

\section{INTRODUCTION}

In many cases, women may experience sexual dysfunction as a result of drug treatment for depression. Selective serotonin reuptake inhibitors (SSRIs) can produce anorgasmia and a reduction in libido in women (Ayd, 1995; Balon, 1995; Feiger et al, 1996; Laumann et al, 1999; Terao, 2001). Notably, SSRIs are used for the treatment of various other disorders, such as anxiety, premenstrual dysphoric disorder, pain syndromes, impulse control disorders, and personality disorders, many of which are more common among women than men (Hensley and Nurnberg, 2002). Adverse side effects of drugs may reduce medication compliance. Therefore, an important area for further investigation is the effects and possible treatment of SSRIs on the sexual function of women.

Although the sexual side effects of SSRIs observed in people have been demonstrated to occur in rodents, studies using animal models to investigate these effects are sparse

\footnotetext{
*Correspondence: Dr CA Frye, Social Science I 12, The University at Albany, SUNY, Albany, NY 12222, USA, Tel: + I 5 I 8442 4836, Fax: + I 518442 4247, E-mail: cafrye@cnsunix.albany.edu
}

Received 7 May 2002; revised 17 July 2002; accepted 5 August 2002
(Vega Matuszczyk et al, 1998). Notably, the majority of studies using animal models to investigate the effects of SSRIs to disrupt sexual functioning have utilized male rodents (Ahlenius et al, 1979; Taylor et al, 1996; Yells et al, 1995; Yells et al, 1994). One study assessed the effects of a SSRI on the sexual receptivity and behavior of female rats. Intact female rats administered fluoxetine $(10 \mathrm{mg} / \mathrm{kg}) \mathrm{had}$ reduced lordosis behavior compared to vehicle-administered control females (Matuszczyk et al, 1998).

There are ample data in the literature to support the idea that serotonin can robustly influence sexual behavior. As early as the 1960s, it was hypothesized that serotonin inhibited sexual receptivity, and more recent evidence supports this idea (Mendelson, 1992; Meyerson, 1964a, b). For example, in female rats, treatments that increase serotonin activity decrease lordosis responses (Allen et al, 1993; Luine and Paden, 1982). These data are consistent with the multitude of reports in the clinical literature that SSRIs induce sexual dysfunction. SSRIs block the function of the presynaptic transporter for serotonin reuptake, but do not appear to block any of the postsynaptic serotonin receptors. This blockade of the presynaptic transporter would thus result in increased serotonin activity, which could explain the negative sexual side effects associated with SSRI treatment. 
There is evidence to suggest that inhibitors of phosphodiesterase 5 (PDE-5), such as sildenafil and zaprinast, can significantly improve SSRI-induced sexual dysfunction in women (Fava et al, 1998; Rosen et al, 1999). Women taking SSRIs who received 50 or $100 \mathrm{mg}$ of sildenafil self-report improved sexual function (Ashton, 1999; Schaller and Behar, 1999; Shen et al, 1999). However, there have been no controlled experimental studies utilizing animal models of sexual dysfunction to confirm that PDE inhibitors can overcome SSRI-induced decrements in sexual functioning.

Sildenafil and zaprinast are selective inhibitors of GMPspecific PDE-5, which is the predominant PDE isoenzyme metabolizing cGMP in the smooth muscle cells of the corpus canvernosum. As cGMP levels are improved, there is increased vasodilation and dilation of the sinusoids in the corpus cavernosum, allowing for increased blood flow, which results in enhanced erections in men. While the majority of the investigations of the actions of PDE inhibitors have focused on erectile dysfunction in men, it is presumed that increased blood flow to the vaginal area of women would also result in enhanced sexual functioning.

The present studies investigated the effects of a SSRI, fluoxetine, and/or a PDE-5 inhibitor, zaprinast, to influence sexual sensitivity of female hamsters at the peak and termination of behavioral estrus using lateral displacement. Lateral displacement is a sensitive measure of the sensitivity of female hamsters to sexually relevant stimuli. The ovulation of naturally cycling female hamsters occurs every 4 days in coordination with behavioral estrus. Behavioral estrus is characterized by female hamsters' display of lordosis in response to sexually relevant stimuli. Female hamsters are unique in that they maintain the lordosis posture, elevation of the head and tail, and dorsoflection of the back, for minutes at a time. Hamsters in behavioral estrus assume the lordosis posture in the presence of sexually relevant stimuli. They then make pelvic adjustments in response to stimulus behavior such as sniffing and licking the perineal region prior to initiating a mount and during mounting when males engage in preinsertion thrusting (Noble, 1979a, b; Ostrowski et al, 1979, 1981). Dogs (Hart, 1970), cats (Diakow, 1971), and rats (Kow \& Pfaff, 1973-1974) show similar patterns of pelvic adjustments. In hamsters, because of their tonic maintenance of the lordosis posture, these pelvic adjustments are observable and can be measured with a high degree of interobserver reliability. The pelvic adjustments, referred to as lateral displacement, depend upon the stimulation applied to the perineum and fluctuate with behavioral estrus. Lateral displacement facilitates insertion by the male during mating (Noble, 1979a, b, 1980): anesthetizing the perineum of female hamsters eliminates lateral displacement, and disrupts copulatory behavior of male hamsters (Noble, 1979a, b, 1980).

We hypothesize that increasing serotonin activity, by administration of the SSRI fluoxetine, to hamsters that are maximally sensitive to sexual stimuli (at the peak of behavioral estrus) will decrease sexual responsivity, as measured by lateral displacement. Further, it is expected that increasing cGMP levels, with the PDE-5 inhibitor zaprinast, will enhance lateral displacement of hamsters that show less responsivity to sexual stimuli as they near the termination of behavioral estrus. Finally, it is predicted that zaprinast administered to hamsters with maximal sexual sensitivity (peak of behavioral estrus) will override deficits in lateral displacement caused by fluoxetine.

\section{METHODS}

These methods were preapproved by the Institutional Animal Care and Use Committee at SUNY, Albany.

\section{Animals and Housing}

A total of 16 sexually inexperienced female hamsters (Mesocricetus auratus) were obtained from Charles River Laboratories (Kingston, NY) at $\sim 60$ days of age or $100-$ $125 \mathrm{~g}$ of body weight.

Hamsters were group housed, four to a cage, in solid bottom, plastic cages $\left(38 \times 33 \times 17 \mathrm{~cm}^{3}\right)$ in a temperature$\left(22^{\circ} \mathrm{C}\right)$ and humidity-controlled $(60 \%)$ hamster vivarium at SUNY, Albany. Hamsters were on a reversed light dark cycle (light:dark 14:10, lights off at 08:00). Chow and water were available ad libitium in the home cages.

\section{Determination of Behavioral Estrus}

Daily screening was performed of all hamsters between 0700 and $0800 \mathrm{~h}$ to determine those that were in behavioral estrus. Hamsters were placed in an arena with a male who was allowed to investigate the female. If the female exhibited lordosis in response to the stimulus male and/or manual palpation by the experimenter, the female was considered in behavioral estrus and tested in one condition on that day. We have previously demonstrated that hamsters identified as being in behavioral estrus in this fashion show maximal sexual behavior between 0900 and $1100 \mathrm{~h}$ and that responses are significantly reduced later in the day (between 1500 and $1700 \mathrm{~h}$; Frye and Rhodes, 2002). Hamsters were tested once per cycle (ie no more than once a week) with counterbalancing between test times (ie peak and termination of behavioral estrus) to control for order effects. Behavioral estrus, rather than examination of vaginal epithelium, was used as an indicator of hormonal status of hamsters in order to reduce vaginocervical stimulation that occurs when collecting vaginal cytology of hamsters, which has been shown to alter lateral displacement responses (Noble, 1979).

\section{Drugs}

Fluoxetine was obtained from Sigma Chemical Co. (St Louis, MO). The fluoxetine regimen was based on previous reports that demonstrated effects of the drug on aggressive behavior of hamsters (Ferris et al, 1997) and sexual responses of rats (Matuszczyk et al, 1998; Muck-Seler et al, 1996; Page et al, 1999; Vega Matuszczyk et al, 1998). Fluoxetine was administered in a saline vehicle, in a dosage of $10 \mathrm{mg} / \mathrm{kg}$ (i.p.), $60 \mathrm{~min}$ prior to behavioral testing.

Zaprinast was obtained from Sigma Chemical Co. (St Louis, MO). The zaprinast regimen was based on previous reports that the drug increased sexual responses of mice (Pare and Kerchner, 2000). Zaprinast was administered in a vehicle of $25 \%$ DMSO in saline $(\mathrm{v} / \mathrm{v})$, in a dosage of $3 \mathrm{mg} / \mathrm{kg}$ (i.p.), $20 \mathrm{~min}$ prior to behavioral testing. 


\section{Behavioral Testing — Lateral displacement}

The coordination of copulatory interactions in hamsters depends on a cluster of responses to tactile stimuli of the female's perineal region. The lateral displacement methodology has been developed to measure a female hamster's responses to tactile stimulation that mimics that made by the male during a mating sequence (Noble, 1979a, b). The response of female hamsters to tactile stimulation from the male facilitates penile insertion (Noble, 1980) and has been demonstrated, like other reproductively relevant behaviors, to fluctuate across the estrous cycle. The measure of lateral displacement was used as a more robust measure of a female's sensitivity to tactile stimuli (compared to lordosis) as more traditional measures, such as lordosis, have been demonstrated to occur in situations where mating is unlikely (ie among females that are pregnant or that have just been mated), while the lateral displacement response is severely depressed or absent during these times (Wise, 1974).

The lateral displacement methodology was as previously described (Frye and Rhodes, 2002; Noble, 1979a, b; Ostrowski et al, 1981). The female was briefly exposed to a stimulus male until she assumed lordosis. The male was then removed from the test chamber and the experimenter maintained the lordosis posture of the female with manual flank stimulation. A calibrated set of von Frey aesthesiometric probes was manually applied by the experimenter to the perineum in descending order of force. These probes are calibrated in 11 log-unit steps ranging from 0.69 to $75.9 \mathrm{~g}$ of pressure (Ostrowski et al, 1979). The probes were applied in a pulsatile manner (until the female's lateral movement stopped), similar to male-typical stimuli (ie preinsertion thrusting), to the right and left inner zones $( \pm 2 \mathrm{~mm}$ from the ano-vaginal midline) and the right and left outer zones ( $\pm 7 \mathrm{~mm}$ from the ano-vaginal midline). The inner zone of the perineum is typically more sensitive to tactile stimulation than the outer zone and hence generally responds to a lower threshold of stimulation (Frye and Rhodes, 2002). The movement (in $\mathrm{mm}$ ) of the female's perineum in response to stimulation was measured by a ruler positioned along her feet. We have previously demonstrated that total lateral displacement scores decrease as a function of the force of the probes applied to the inner and outer zone of the perineum (Frye and Rhodes, 2002). Scores of lateral displacement for the inner and outer perineum were summed to yield a total lateral displacement score. It has previously been demonstrated that there are no test decay effects with repeated testing in this behavioral assay (Frye and Rhodes, 2002). Notably, there were no overt changes in appearance of the perineum as a function of repeated testing, behavioral estrus, or drug treatment.

\section{Procedure}

Experiment 1: Does fluoxetine reduce lateral displacement of hamsters at the peak of behavioral estrus? Hamsters that were maximally receptive, at the peak of behavioral estrus (between 0900 and $1100 \mathrm{~h}$ ) were administered fluoxetine $(10 \mathrm{mg} / \mathrm{kg}$, i.p.) or vehicle (saline) and tested for effects on lateral displacement $60 \mathrm{~min}$ later. Each hamster was tested in both the fluoxetine and vehicle conditions; the order of initial drug $v s$ vehicle administration was randomized and counterbalanced to prevent order effects.

Experiment 2: Does zaprinast enhance lateral displacement of hamsters late in behavioral estrus? Hamsters later in behavioral estrus $(1500-1700 \mathrm{~h})$ were administered zaprinast $(3 \mathrm{mg} / \mathrm{kg}$, i.p.) or vehicle ( $25 \%$ DMSO in $0.9 \%$ saline) and tested for effects on lateral displacement $20 \mathrm{~min}$ later. Each hamster was tested in both the zaprinast and vehicle conditions; the order of drug $v s$ vehicle administration was randomized and counterbalanced to prevent order effects.

Experiment 3: Can zaprinast overcome fluoxetine's inhibitory effects on lateral displacement of hamsters at the peak of behavioral estrus? Hamsters that were maximally receptive at the peak of behavioral estrus (between 0900 and $1100 \mathrm{~h}$ ) were administered fluoxetine ( $10 \mathrm{mg} / \mathrm{kg}$, i.p.) or vehicle (saline), followed $40 \mathrm{~min}$ later by zaprinast or vehicle ( $25 \%$ DMSO in $0.9 \%$ saline). Hamsters were tested for lateral displacement $20 \mathrm{~min}$ after zaprinast administration. Each hamster was tested in each of the four drug regimens: vehicle (saline)+vehicle (DMSO); Fluox (fluoxetine+vehicle (DMSO)); Zap (vehicle (saline)+zaprinast); Fluox and Zap (fluoxetine+zaprinast). The conditions under which hamsters were tested were randomized and counterbalanced to prevent order effects.

\section{Statistical Analyses}

One-way analyses of variance (ANOVAs) were utilized to examine effects of drug treatment on lateral displacement. Factors revealed as significant in the overall ANOVAs were confirmed with least-squares means post hoc tests to ascertain group differences. The alpha level for statistical significance was $P \leqslant 0.05$.

\section{RESULTS}

Experiment 1: Fluoxetine decreases lateral displacement of hamsters at the peak of behavioral estrus

Fluoxetine administration to hamsters at the peak of behavioral estrus significantly diminished lateral displacement responses compared to vehicle administration. Total lateral displacement responses for the more sensitive inner $(\mathrm{F}(1,15)=32.47, \quad P<0.01)$ and the less sensitive outer $(\mathrm{F}(1,15)=30.09, \quad P<0.01) \quad$ zones were significantly decreased by fluoxetine $v s$ vehicle administration (see Figure 1).

\section{Experiment 2: Zaprinast enhances lateral displacement} of hamsters late in behavioral estrus

Zaprinast administration to hamsters late in behavioral estrus significantly enhanced lateral displacement responses compared to vehicle administration. Total lateral displacement responses for both the inner $(\mathrm{F}(1,15)=27.38, P<0.01)$ and the outer $(F(1,15)=18.61, P<0.01)$ zones were significantly increased by zaprinast compared to vehicle administration (see Figure 2). 


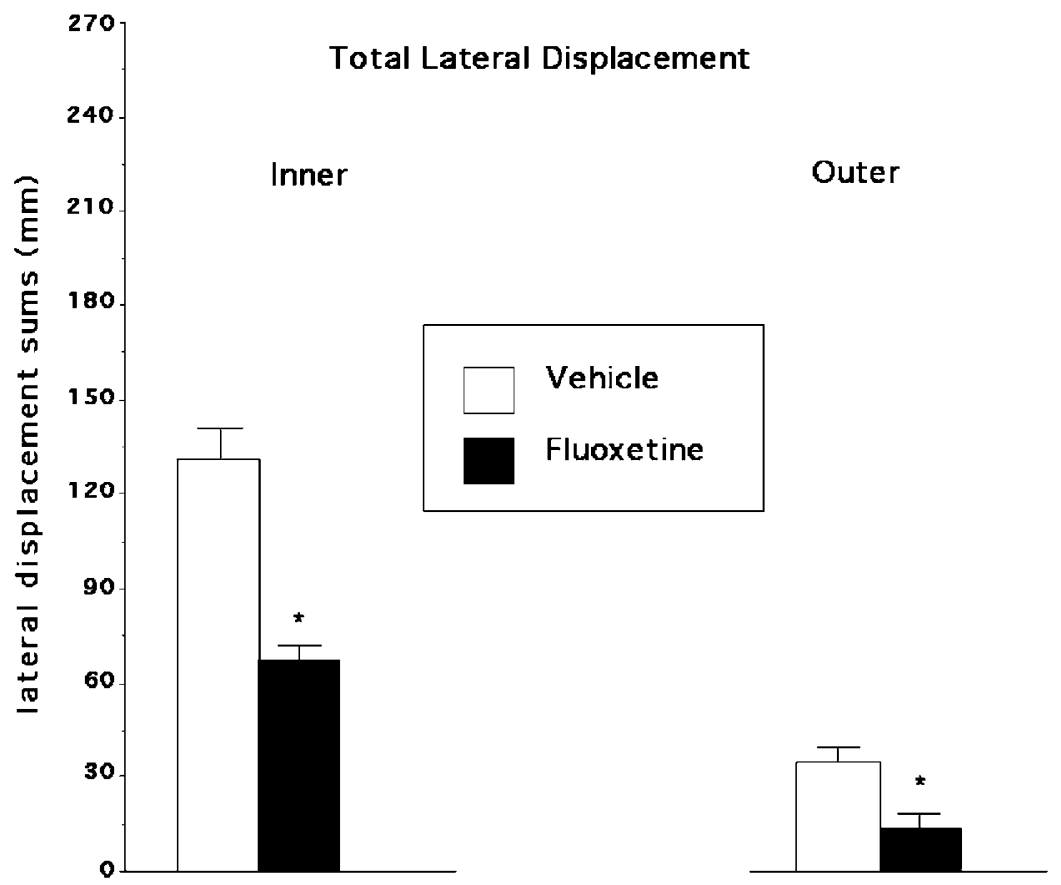

Figure I Total lateral displacement of hamsters that received vehicle (open bar; $n=16$ ) or fluoxetine (dotted bar; $n=16$ ). *indicates a significant difference $(P<0.05)$ compared to vehicle.

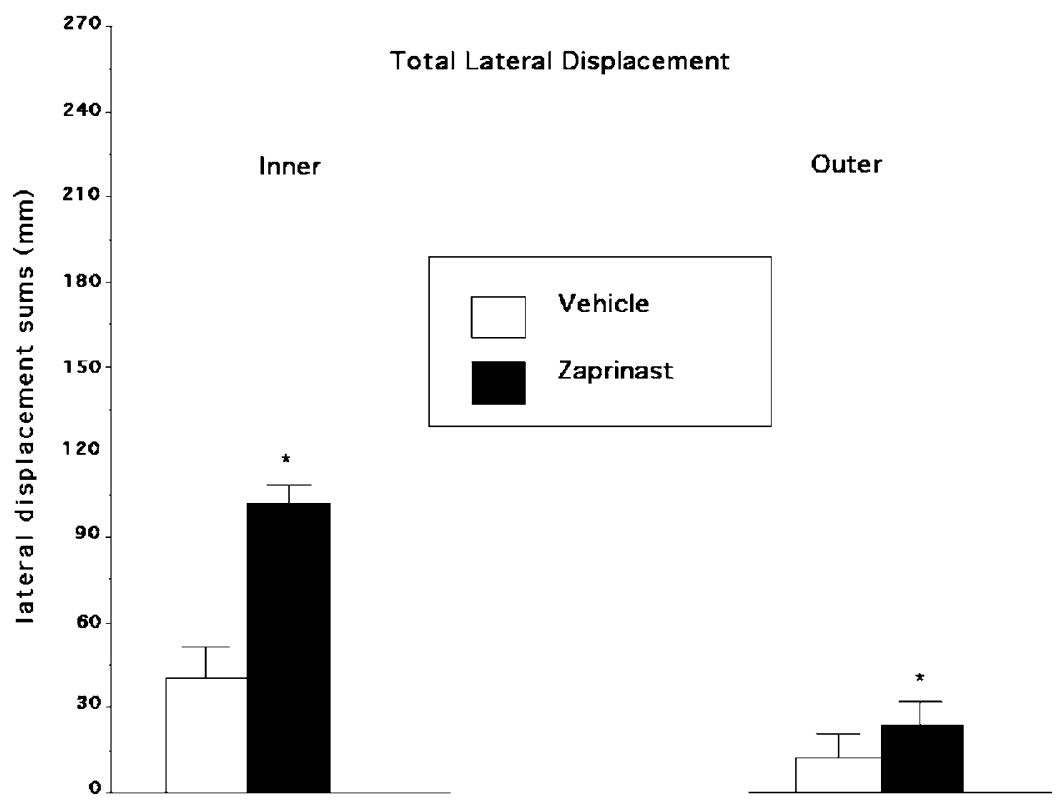

Figure 2 Total lateral displacement of hamsters that received vehicle (open bar; $n=16$ ) or zaprinast (diagonally striped bar; $n=16$ ). *indicates a significant difference $(P<0.05)$ compared to vehicle.

Experiment 3: Zaprinast attenuates fluoxetine's inhibitory effects on lateral displacement of hamsters at the peak of behavioral estrus

Zaprinast administration to hamsters that had previously received fluoxetine early in behavioral estrus significantly increased total inner and outer lateral displacement responses compared to those produced by fluoxetine combined with later administration of vehicle. Total lateral displacement responses for both the inner $(\mathrm{F}(3,15)=22.89$, $P<0.01)$ and the outer $(\mathrm{F}(3,15)=29.31, P<0.01)$ zones were significantly different across groups (see Figure 3). Consistent with the results from Experiment 1, fluoxetine administration decreased total inner and outer scores of hamsters when administered early in behavioral estrus compared to vehicle administration. Zaprinast, when administered early in behavioral estrus, did not further increase total inner and outer scores, above that seen with vehicle administration. However, when fluoxetine administration was followed by zaprinast, total lateral displacement scores for both the inner and outer zones were no longer 


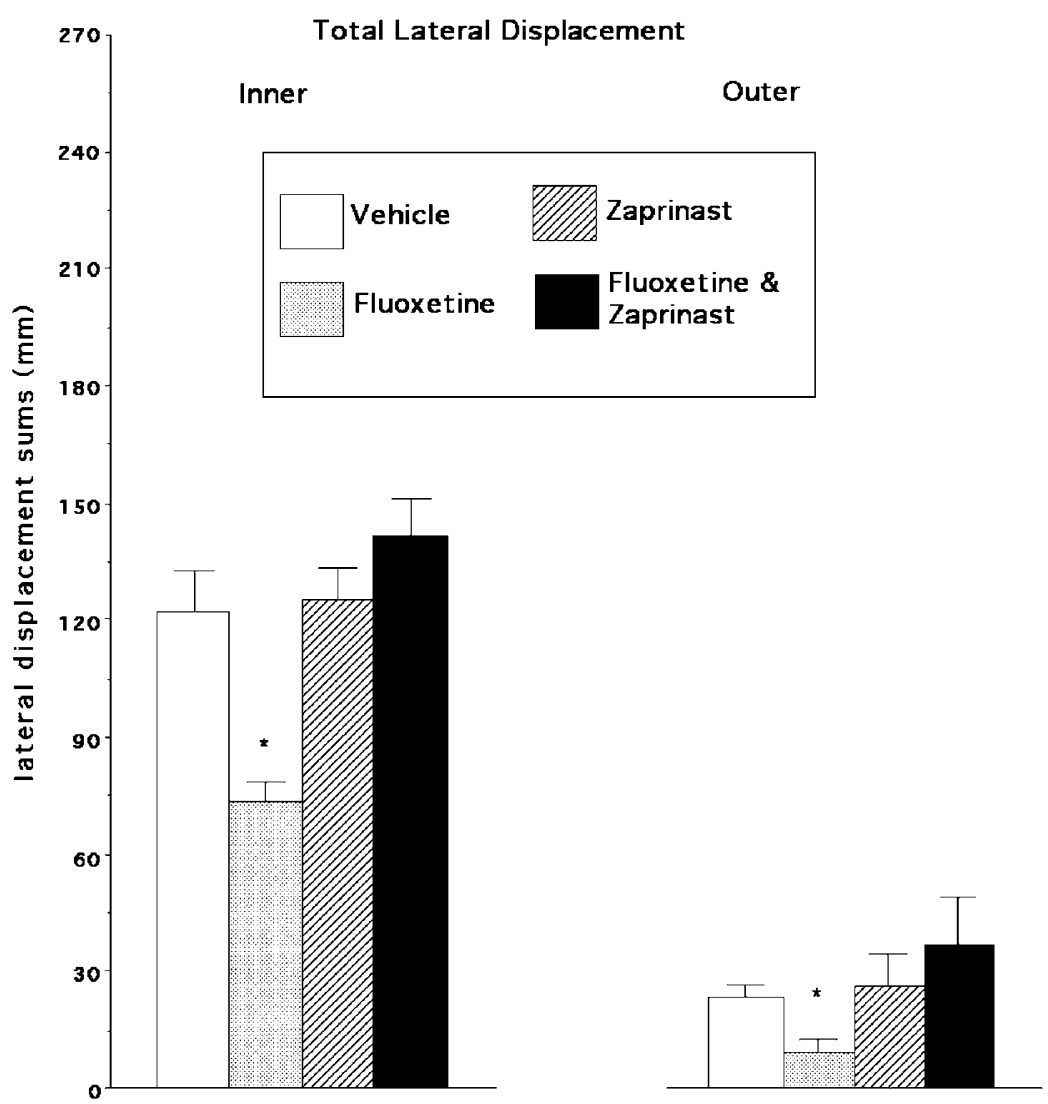

Figure 3 Total lateral displacement of hamsters that received vehicle/vehicle (open bar; $n=16$ ), fluoxetine/vehicle (dotted bar; $n=16$ ), vehicle/zaprinast (diagonally striped bar), or fluoxetine/zaprinast (horizontally striped bar). *indicates a significant difference $(P<0.05)$ compared to all other groups.

reduced. Instead, the total lateral displacement scores were reinstated to high levels that were comparable to those seen following only vehicle administration to hamsters at the peak of behavioral estrus.

\section{DISCUSSION}

The present results supported our hypothesis that administration of fluoxetine or zaprinast alone, or coadministration of fluoxetine and zaprinast, would alter the lateral displacement response of hamsters that are differentially sensitive to sexually relevant stimuli (because of testing at different time points in behavioral estrus). Fluoxetine administration significantly lowered total lateral displacement compared to that seen following vehicle administration to hamsters that were maximally sensitive to sexual stimuli (Experiment 1). Zaprinast significantly increased total lateral displacement scores compared to that seen following vehicle administration to hamsters that were less sensitive to sexual stimuli (Experiment 2). Deficits in lateral displacement produced by fluoxetine administration to hamsters, maximally sensitive at the peak of behavioral estrus, were overcome by coadministration of zaprinast, but not vehicle (Experiment 3). Together, these data indicate that fluoxetine can decrease the sexual response of hamsters that, because of cyclic fluctuations, show greater lateral displacement responses. Zaprinast can enhance the endogenous reductions in lateral displacement scores seen of hamsters late in behavioral estrus. Most importantly, zaprinast could override deficits in lateral displacement produced by fluoxetine administration to hamsters at the peak of behavioral estrus.

Our results confirm that SSRIs produce sexual dysfunction and extend the current literature to demonstrate that PDE inhibitors can overcome these effects. Previous research has demonstrated that SSRIs can induce sexual dysfunction in male rodents (Ahlenius et al, 1979; Taylor et al, 1996; Yells et al, 1995; Yells et al, 1994); however, few studies have investigated the effects of SSRIs on the sexual function of female rodents (Matuszczyk et al, 1998). As well, PDE inhibitors can facilitate sexual behavior of female rats. Ovariectomized, estrogen-treated rats administered a subthreshold dose of progesterone and a PDE inhibitor (1methyl, 3-isobutylxanthine or theophylline) had enhanced lordosis responses compared to rats treated with estrogen and a subthreshold dose of progesterone alone (Beyer and Canchola, 1981). The present studies demonstrate novel findings using this animal model of female sexual response that the SSRI fluoxetine can induce sexual dysfunction and that sexual behavior of female hamsters can be facilitated with the administration of the PDE-5 inhibitor zaprinast. Further, the present data indicate that sexual dysfunction induced by fluoxetine can be ameliorated with the coadministration of zaprinast in the lateral displacement model.

Although the exact mechanism of SSRI's therapeutic effects on depression are not known, fluoxetine does have 
effects on the serotonin system. It is well known that the serotonin system is important in the modulation of female sexual response. Activation of $5-\mathrm{HT}_{1 \mathrm{~A}}$ receptors generally inhibits lordosis of rats (Fernandez-Guasti et al, 1987; Gonzalez et al, 1997; Hebert et al, 1995). Long-term treatment with SSRIs enhances serotonin neurotransmission, and it is hypothesized that stimulation of $5-\mathrm{HT}_{1 \mathrm{~A}}$ receptors is associated with the antidepressant and anxiolytic effects of these drugs (Uphouse, 2000). Hence, it is possible that SSRI-induced sexual dysfunction is partly because of activation of $5 \mathrm{HT}_{1 \mathrm{~A}}$ receptors. A better understanding of the neural substrates for female sexual behavior can be attained by examining the effects of antidepressant drugs on sexual responses using this model of lateral displacement. Such an approach may elucidate important neural substrates contributing to sexual dysfunction in women.

The data presented here are exciting as they suggest that zaprinast, a PDE-5 inhibitor, can attenuate deficits in sexual responses of female hamsters induced by fluoxetine, an SSRI. However, we must be cautious in our interpretation of the data. First, the model utilized in the present studies is a model of sexual response and sexual sensitivity, not one of sexual desire or motivation. Although it should be noted that people experiencing depression might initially experience a loss of sexual desire or motivation, treatment with SSRIs generally overcomes this ahedonia. However, the deficits in sexual response or sensitivity induced by SSRI treatment often negate the positive effects of SSRIs on sexual desire or motivation. The model utilized addresses this issue by examining the effects of a PDE- 5 inhibitor to overcome deficits in sexual response caused specifically by SSRI administration. Second, generalizing data from a rodent model to humans is always difficult, but in this case even more so as hamsters are not representative of other rodents. For example, hamsters metabolize many drugs in a different manner than do other rodents (Brodie, 1964). In the present experiments, this criticism does not seem to apply as the drug dosages used were analogous to dosages used in previous studies with rats.

The neurochemical basis of the ability of PDE inhibitors to overcome deficits in sexual functioning induced by SSRIs is not yet fully understood. There is some evidence to suggest that PDE inhibitors may alter serotonin levels (Freitag et al, 1998). However, the exact interactions between PDE inhibitors and SSRIs that give rise to these effects are unknown. One hypothesis is that SSRIs may alter steroid metabolism enzymes (Griffin and Mellon, 1999) that are important for the formation of progestins, which are integral for the facilitation of sexual responses (Frye, 2001). It is possible that PDE inhibitors may also target these steroid metabolism enzymes; however, this is a subject of ongoing investigation in our laboratory.

In conclusion, the negative impact of SSRIs on sexual function is a major clinical problem, and the possibility to counteract such effects by PDE inhibitors is hence of considerable importance. To our knowledge, this is the first report that PDE inhibitors may antagonize negative effects of SSRIs on sexual responses of animals. This is important for two reasons. First, it encourages further clinical research regarding the possibility of PDE inhibitors to ameliorate SSRI-induced sexual dysfunction in women. Second, it provides a model by which these kinds of drug interactions can be investigated in animals.

\section{ACKNOWLEDGEMENTS}

This research was supported by Grant 98-96263 from the National Science Foundation. The technical assistance provided by Zach Simpson and Andrew Slater is greatly appreciated.

\section{REFERENCES}

Ahlenius S, Heimann M, Larsson K (1979). Prolongation of the ejaculation latency in the male rat by thioridazin and chlorimipramine. Psychopharmacology 65: 137-140.

Allen DL, Renner KJ, Luine VN (1993). Pargyline-induced increase in serotonin levels: correlation with inhibition of lordosis in rats. Pharmacol Biochem Behav 45: 837-841.

Ashton AK (1999). Sildenafil treatment of paroxetine-induced anorgasmia in a woman. Am J Psychol 156: 800.

Ayd FJ (1995). Pertinent medical intelligence: fluoxetine's impact on sexual function. Md Med J 44: 526-527.

Baylon R (1995). Fluoxetine and sexual dysfunction. JAMA 273: 1489.

Beyer C, Canchola E (1981). Facilitation of progesterone induced lordosis behavior by phosphodiesterase inhibitors in estrogen primed rats. Physiol Behav 27: 731-733.

Brodie BB (1964). Difficulties in transposing experimental results obtained with animals to man. Actual Pharmacol (Paris) 17: 1-40.

Diakow C (1971). Effects of genital desensitization on mating behavior and ovulation in the female cat. Physiol Behav 7: 47-54.

Fava M, Rankin MA, Alpert JE, Nierenberg AA, Worthington JJ (1998). An open trial of oral sildenafilin antidepressant-induced sexual dysfunction. Psychother Psychosom 67: 328-331.

Feiger A, Kiev A, Shrivastava RK, Wisselink PG, Wilcox CS (1996). Nefazodone versus sertraline in outpatients with major depression: focus on efficacy, tolerability, and effects on sexual function and satisfaction. $J$ Clin Psychiatry 57: 53-62.

Fernandez-Guasti A, Ahlenius S, Hjorth S, Larsson K (1987). Separation of dopaminergic and serotonergic inhibitory mechanisms in the mediation of estrogen-induced lordosis behaviour in the rat. Pharmacol Biochem Behav 27: 93-98.

Ferris CF, Melloni Jr RH, Koppel G, Perry KW, Fuller RW, Delville $Y$ (1997). Vasopressin/serotonin interactions in the anterior hypothalamus control aggressive behavior in golden hamsters. $J$ Neurosci 17: 4331-4340.

Freitag A, Wessler I, Racke K (1998). Phosphodiesterase inhibitors suppress alpha2-adrenoceptor-mediated 5-hydroxytryptamine release from tracheae of newborn rabbits. Eur $J$ Pharmacol 354: $67-71$.

Frye CA (2001). The role of neurosteroids and non-genomic effects of progestins and androgens in mediating sexual receptivity of rodents. Brain Res Brain Res Rev 37: 201-222.

Frye CA, Rhodes ME (2002). Inhibiting progesterone metabolism in the ventral tegmental area attenuates lateral displacement of hamsters. Horm Behav (submitted).

Gonzalez MI, Greengrass P, Russell M, Wilson CA (1997). Comparison of serotonin receptor numbers and activity in specific hypothalamic areas of sexually active and inactive female rats. Neuroendocrinology 66: 384-392.

Griffin LD, Mellon SH (1999). Selective serotonin reuptake inhibitors directly alter activity of neurosteroidogenic enzymes. Proc Natl Acad Sci USA 96: 13512-13517.

Hart BL (1970). Mating behavior in the female dog and the effect of estrogen on sexual reflexes. Horm Behav 1: 93-104. 
Hebert TJ, Menard CS, Dohanich GP (1995). Inhibition of lordosis in female hamsters and rats by 8-OH-DPAT treatment. Physiol Behav 57: 523-527.

Hensley PL, Nurnberg HG (2002). SSRI sexual dysfunction: a female perspective. J Sex Mar Ther 28: 143-153.

Kow LM, Pfaff DW (1973-1974). Effects of estrogen treatment on the size of receptive field and response threshold of pudendal nerve in the female rat. Neuroendocrinology 13: 299-313.

Laumann EO, Paik A, Rosen RC (1999). Sexual dysfunction in the United States: prevalence and predictors. JAMA 281: 537-544.

Luine VN, Paden CM (1982). Effects of monoamine oxidase inhibition on female sexual behavior, serotonin levels and type A and B monoamine oxidase activity. Neuroendocrinology 34: 245-251.

Matuszczyk JV, Larsson K, Eriksson E (1998). Subchronic administration of fluoxetine impairs estrous behavior in intact female rats. Neuropsychopharmacology 19: 492-498.

Mendelson SD (1992). A review and reevaluation of the role of serotonin in the modulation of lordosis behavior in the female rat. Neurosci Biobehav Rev 16: 309-350.

Meyerson BJ (1964a). The effect of neuropharmacological agents on hormone-activated estrus behavior in the spayed rat. Arch Int Pharmacodyn Ther 150: 4-33.

Meyerson BJ (1964b). Central nervous monoamines and hormoneinduced estrus behavior in the spayed rat. Acta Physiol Scand 63: 3-32.

Muck-Seler D, Jevric-Causevic A, Diksic M (1996). Influence of fluoxetine on regional serotonin synthesis in the rat brain. $J$ Neurochem 67: 2434-2442.

Noble RG (1979a). The sexual responses of the female hamster: a descriptive analysis. Physiol Behav 23: 1001-1005.

Noble RG (1979b). Limited coital stimulation facilitates sexual responses of the female hamster. Physiol Behav 23: 1007-1010.

Noble RG (1980). Sex responses of the female hamster: effects on male performance. Physiol Behav 24: 237-242.

Ostrowski NL, Noble RG, Reid LD (1981). Opiate antagonists and sexual behavior in female hamsters. Pharmacol Biochem Behav 14: $881-888$.
Ostrowski NL, Stapleton JM, Noble RG, Reid LD (1979). Morphine and naloxone's effects on sexual behavior of the female golden hamster. Pharmacol Biochem Behav 11: 673-681.

Page ME, Detke MJ, Dalvi A, Kirby LG, Lucki I (1999). Serotonergic mediation of the effects of fluoxetine, but not desipramine, in the rat forced swimming test. Psychopharmacology 147: 162-167.

Pare ATM, Kerchner M (2000). Effects of zaprinast on sexual behavior, acoustic startle, and activity in the bulbectomized mouse, an animal model for depression. Soc Neurosci Abs 26: 215.

Rosen RC, Lane RM, Menza M (1999). Effects of SSRIs on sexual function: a critical review. J Clin Psychopharmacol 19: 67-85.

Schaller JL, Behar D (1999). Sildenafil citrate for SSRI-induced sexual side effects. Am J Psychiatry 156: 156-157.

Shen WW, Urosevich Z, Clayton DO (1999). Sildenafil in the treatment of female sexual dysfunction induced by selective serotonin reuptake inhibitors. J Reprod Med 44: 535-442.

Taylor G, Bardgett M, Csernansky J, Early T, Haller J et al (1996). Male reproductive systems under chronic fluoxetine or trimipramine treatment. Physiol Behav 59: 479-485.

Terao T (2001). Female sexual dysfunction and antidepressant use. Am J Psychiatry 158: 326-327.

Uphouse L (2000). Female gonadal hormones, serotonin, and sexual receptivity. Brain Res Brain Res Rev 33: 242-257.

Vega Matuszczyk JV, Larsson K, Erikkson E (1998). The selective serotonin reuptake inhibitor fluoxetine reduces sexual motivation in male rats. Pharmacol Biochem Behav 60: 527-532.

Wise DA (1974). Aggression in the female golden hamster: effect of reproductive state and social isolation. Horm Behav 5: 235-250.

Yells D, Prendergast MA, Hendricks SE, Miller ME (1995). Monoaminergic influences on temporal patterning of sexual behavior in male rats. Physiol Behav 58: 847-852.

Yells D, Prendergast MA, Hendricks SE, Nakamura M (1994). Fluoxetine-induced inhibition of male rat copulatory behavior: modulation by lesions of the nucleus paragigantocellularis. Pharmacol Biochem Behav 49: 121-127. 